\title{
Telomerase activity is more significant for predicting the outcome of IVF treatment than telomere length in granulosa cells
}

\author{
Wenjun Wang ${ }^{*}$, Hong Chen ${ }^{*}{ }^{+}$, Ruiqi Li, Nengyong Ouyang, Jinghua Chen, Lili Huang, \\ Meiqi Mai, Ningfeng Zhang, Qingxue Zhang and Dongzi Yang \\ Department of Obstetrics and Gynecology, Reproductive Medicine Centre, Sun Yat-Sen Memorial Hospital, \\ Sun Yat-Sen University, Guangzhou, 510120, People's Republic of China \\ Correspondence should be addressed to W Wang; Email: wenjungzcn@163.com \\ *(W Wang and $\mathrm{H}$ Chen contributed equally to this work) \\ ${ }^{+}$(H Chen is now at Department of Assisted Reproduction, Shanghai Ninth People's Hospital, Shanghai Jiaotong University, \\ Shanghai, People's Republic of China, finished the study in Sun Yat-Sen Memorial Hospital)
}

\begin{abstract}
Our previous study has demonstrated that luteinized granulosa cells (GCs) have the potential to proliferate and that the telomerase activity (TA) of luteinized GCs may predict the clinical outcomes of IVF treatment. However, in the field of telomere research, there have always been different opinions regarding the significance of TA and telomere length (TL). Thus, in the present study, we compared the effects of these two parameters on IVF treatment outcomes in the same individuals. TL did not differ significantly between the pregnant group and the non-pregnant group. The TA, number of retrieved oocytes and rate of blastocyst transfer were significantly higher in the pregnant group than in the non-pregnant group $(0.8825 \mathrm{OD} \times \mathrm{mm}, 12.75 \pm 2.20$ and $34.48 \%$, respectively, in the pregnant group vs $0.513 \mathrm{OD} \times \mathrm{mm}, \mathbf{1 1 . 6 0} \pm \mathbf{0 . 9 3}$ and $\mathbf{1 4 . 8 9 \%}$, respectively, in the non-pregnant group $(P<0.05))$, while basal FSH level was lower in the pregnant group than in the non-pregnant group. The subjects did not differ with regard to ovarian stimulation or other clinical characteristics. A TA increase of $1 \mathrm{OD} \times \mathrm{mm}$ increased the chance of becoming pregnant 4.769-fold (odds ratio: 5.769 , 95\% $\mathrm{CI}$ : 1.434-23.212, $P<0.014)$. The areas under the receiver operating characteristic curves were 0.576 for TL and 0.674 for TA $(P=0.271$ and $P<0.012$ respectively). The corresponding cut-off points were 4.470 for TL and $0.650 \mathrm{OD} \times \mathrm{mm}$ for TA. These results demonstrate that TA is a better predictor of pregnancy outcomes following IVF treatment than TL. No other clinical parameters, including age, baseline FSH level or peak oestradiol level, distinguished between the pregnant group and the non-pregnant group as effectively as TA.

Reproduction (2014) 147 649-657
\end{abstract}

\section{Introduction}

Telomeres are the physical ends of eukaryotic chromosomes. They consist of a 5-15 kb-long tandem repeat hexanucleotide sequence (TTAGGG) $n$ that protects the ends of the double-stranded DNA (Blackburn 2001). Hence, telomeres play essential roles in the maintenance of chromosomal stability and cell viability.

A possible relationship between telomeres and reproduction has recently been reported. There is evidence that telomere length (TL) is longer in the oocytes of women who become pregnant than in those of women who fail to become pregnant after IVF treatment (Keefe et al. 2007). A study of human sister oocytes collected during IVF procedures has found that TL can predict oocyte development (Keefe et al. 2007). Even the TLs of spare oocytes have been found to be associated with pregnancy outcomes following IVF treatment (Keefe et al. 2006). The study carried out by Dorland et al. (1998) showed that women with fertility disorders had significantly longer lymphocyte TLs than did a group of fertile women of similar ages. This result indicates that TL studies examining actual embryo transfers may be more accurate than those using spare oocytes, sister oocytes or other somatic cells. Only one study (Treff et al. 2011) has shown that TL in polar bodies predicts aneuploidy in linked embryos. There is evidence suggesting that short telomeres resulting from telomerase deficiency can disturb oocyte function by acting on cumulus cells peripherally distributed over oocytes (Liu et al. 2002). However, this result does not mean that longer telomeres do not have any effects. Wan et al. (2012) reported that chromosomes from cirrhotic cases had a significantly longer relative TL (RTL) than those from non-cirrhotic controls. Subjects with long RTLs have been found to have a significantly 
increased risk of cirrhosis. This result suggests that in certain conditions TL predisposes subjects to unfavourable outcomes. A widely accepted model holds that compensation for TL mainly depends on telomerase, a specialised ribonucleoprotein complex.

Granulosa cells (GCs) are the most important somatic cells for determining the final size of preovulatory follicles. Therefore, we sought to determine whether TL and telomerase activity (TA) in GCs are associated with oocyte quality, embryo quality or IVF treatment outcomes. To date, only case-control studies have been used to investigate GC TL in women with or without diminished ovarian reserves. The GC telomeres of women with diminished ovarian reserves have been found to be significantly shorter than those of controls (Buttsa 2006). In addition, several studies have demonstrated detectable TA in the GCs of diverse species, including pigs, cattle and humans (Lavranos et al. 1999, Liu \& Zhu 2003, Tomanek et al. 2008). There have been no reports on predicting IVF treatment outcomes via TA and TL.

Our previous study has demonstrated that luteinized GCs have the potential to proliferate and that the TA of luteinized GCs may predict the clinical outcomes of IVF treatment (Chen et al. 2011). Therefore, we carried out the present study to determine whether TL and TA are correlated with oocyte and embryo quality and with pregnancy outcomes following IVF treatment in a group of women with normal ovarian function. In addition, we evaluated which measure (TL or TA) was more valuable for predicting IVF treatment outcomes.

\section{Materials and methods}

Patient selection

This study was conducted in patients who enrolled in the assisted reproduction programme at the Reproductive Medicine Centre of Sun-Yat-Sen Memorial Hospital between September 2009 and April 2013. During the study period, 76 women aged between 23 and 38 years who underwent their first fresh cycle of IVF were recruited, and informed consent to use their follicular fluid (FF) in this study was obtained. The inclusion criteria were a regular menstrual cycle (every 24-33 days), a normal level of basal serum follicle-stimulating hormone ( $\mathrm{FSH} \leq 8.78 \mathrm{IU} / \mathrm{l})$ and conventional IVF treatment using the long gonadotrophin-releasing hormone $(\mathrm{GNRH})$ agonist protocol. The exclusion criteria included using medications, having a history of ovarian surgery known to affect ovarian function in the 3 months before the study, and diagnosed gynaecological disease such as polycystic ovary syndrome, hyperprolactinaemia, endometrial cysts, functional or organic ovarian cysts, and uterine myoma. The 76 women who were recruited were divided into a pregnant group and a non-pregnant group.

\section{Treatment procedure}

The long GNRH agonist protocol described below was followed. Before combined FSH (Merck Serono, or Puregon, Organon, Barcelona, Spain) and human menopausal gonadotrophin (Gn) (Livzon, Zhuhai, China) stimulation, which was used to enhance multiple follicle development, the patients underwent pituitary desensitisation through an i.m. injection of triptorelin acetate (Diphereline; Ipsen Pharma Biotech. Signes, France). The Gn dose was adjusted according to the ovarian response, which was monitored by transvaginal ultrasound and serum oestradiol $\left(\mathrm{E}_{2}\right)$ concentrations. Ovulation was induced by injecting human chorionic gonadotrophin (HCG) (Livzon, or Ovidrel, Merck Serono) when no spontaneous luteinizing hormone (LH) surge was detected. The cumulus-oocyte complexes were retrieved $36 \mathrm{~h}$ after HCG injection by aspiration under transvaginal ultrasound guidance. The oocytes were classified as 'mature' if they had a fully expanded and stretchable, homogeneous cumulus with a radiating corona layer and a visible polar body. Fertilisation was assessed 16-18 h after IVF or ICSI by examining the oocytes for evidence of pronucleus formation and a second polar body. The zygotes with one or two pronuclei were cultured, and embryo cleavage was assessed after $24 \mathrm{~h}$. The embryos were identified as grade I (good quality) if they had two to four blastomeres of equal size and $<20 \%$ fragmentation on day 2, had more than six blastomeres of equal size and $<20 \%$ fragmentation on day 3 , or formed compact/morula embryos or early blastocysts on day 4. Embryo transfer was performed $2-3$ or 5 days after oocyte collection. Three embryos were transferred into the patients who were aged $\geq 35$ years, and two embryos were transferred into the patients who were aged $<35$ years. Clinical pregnancy was determined by the presence of a gestational sac and a heartbeat by a transvaginal ultrasound performed 7 weeks after embryo transfer.

\section{Assay methods}

Independent investigators, who were blinded to the clinical histories, measured TL using quantitative real-time PCR (qPCR) and determined TA using the telomeric repeat amplification protocol (TRAP) followed by non-denaturing PAGE silver staining.

\section{GC isolation}

A pooled collection of FF was obtained from each patient by follicular aspirates collected during oocyte retrieval. After the completion of oocyte collection and the isolation of cumulusoocyte complexes, the FF was immediately transported for analysis in a thermo-container at a constant temperature of $37^{\circ} \mathrm{C}$. The GCs were isolated by $50 \%$ density-gradient centrifugation in a Ficoll solution (Lymphoprep, AXIS-SHIELD, Oslo, Norway) for 15 min at $720 \mathrm{~g}$ at room temperature and were then washed two to three times with PBS (SAGE, Trumbull, CT, USA). The red blood cells interspersed with the GCs were lysed by the addition of 1-3 $\mathrm{ml}$ of a lysis buffer (Beyotime, Haimen, China). The viability of GCs, as assessed by trypan blue (Sigma) staining, was $\sim 75 \%$ (or $\sim 2 \times 10^{5}$ cells) in all the patients. The purified GCs were snap-frozen in liquid nitrogen and stored at $-80^{\circ} \mathrm{C}$ until protein isolation.

\section{TA assay}

TA was assayed using a commercial kit (TRAPeze, Telomerase Detection Kit, Roche Applied Science) that employed a modified TRAP. Briefly, cell extracts were prepared by lysing the GCs with 


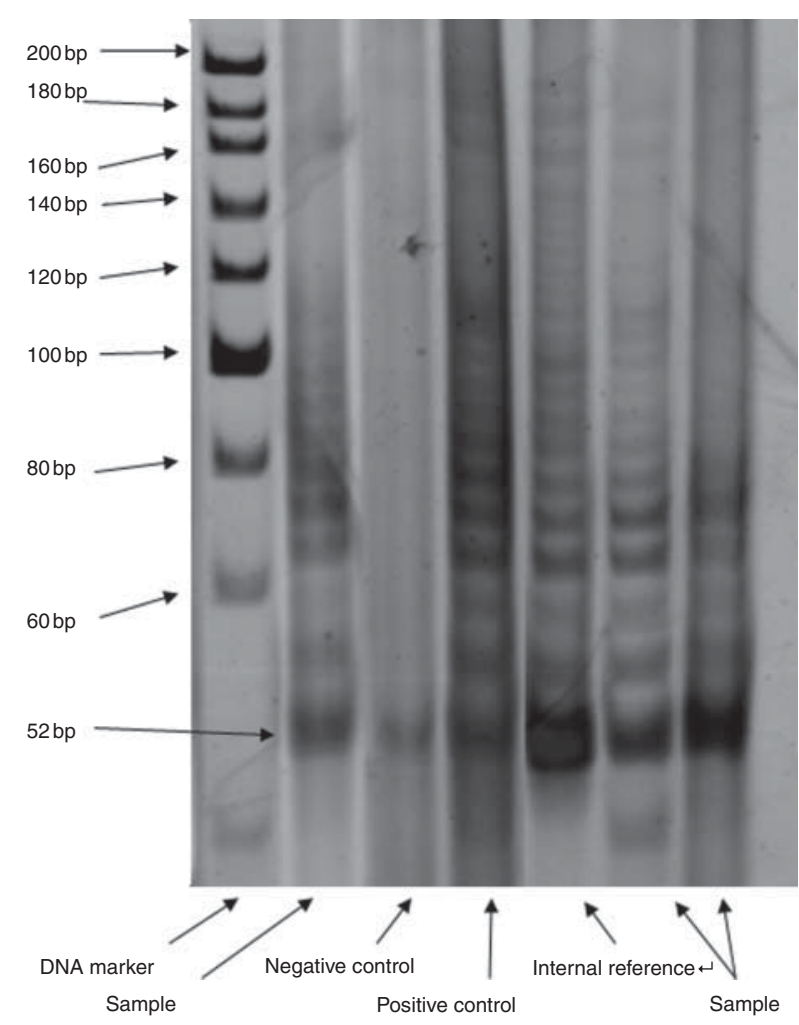

Figure 1 Levels of TA in GCs.

an ice-cold lysis reagent, and $175 \mu \mathrm{l}$ of the supernatant were collected to ensure that no cellular debris from the pelleted cells was transferred. Protein concentrations were measured using BCA kits (Shenergy Biocolor Bioscience and Technology Company, Shanghai, China), and the extracts were flash-frozen with liquid nitrogen as aliquots and stored at $-80^{\circ} \mathrm{C}$ until assayed. The cell extracts were heat-treated for $10 \mathrm{~min}$ at $85^{\circ} \mathrm{C}$ before the TRAP reaction to inactivate the telomerase protein and obtain a negative control. The positive control (human kidney 293 cells) was provided with the assay kit. For each sample and control, $14.63 \mu \mathrm{g}$ of total cell protein were added to $25 \mu \mathrm{l}$ of a reaction mixture (Tris buffer, telomerase substrate, primers, nucleotides, Taq polymerase for one-step telomerase-mediated primer elongation, biotin-labelled P1-TS primer, P2 primer and DNA/RNA-free sterile water (Promega)) to a final volume of $50 \mu \mathrm{l}$ per assay for PCR amplification. The mixture was transferred to a Biometra Tgradient PCR thermocycler (Biometra, Germany) for primer elongation at $37^{\circ} \mathrm{C}$ for $30 \mathrm{~min}$, telomerase deactivation at $94{ }^{\circ} \mathrm{C}$ for $5 \mathrm{~min}, 33$ cycles of amplification $\left(94^{\circ} \mathrm{C}\right.$ for $30 \mathrm{~s}, 50^{\circ} \mathrm{C}$ for $30 \mathrm{~s}$ and $72{ }^{\circ} \mathrm{C}$ for $90 \mathrm{~s}$ ) and one cycle of $72{ }^{\circ} \mathrm{C}$ for $10 \mathrm{~min}$. Non-denaturing PAGE (native PAGE) on a $15 \%$ polyacrylamide gel was used to visualise and analyse the PCR products. Specifically, $10 \mu \mathrm{l}$ of each DNA sample were mixed with $2 \mu \mathrm{l}$ of $6 \times$ DNA loading buffer (TAKARA, Kyoto, Japan) and separated by electrophoresis with a constant electric power of $30 \mathrm{~W}$ at $4{ }^{\circ} \mathrm{C}$ for $3.5 \mathrm{~h}$ after $1 \mathrm{~h}$ of pre-electrophoresis under the same conditions. After the completion of electrophoretic migration, the polyacrylamide gel was incubated with silver stain to identify the telomere DNA bands. The samples were considered to be TA positive if the DNA ladders in the polyacrylamide gel had
6 bp intervals, as shown in Fig. 1. A relative quantitative analysis of the bands was carried out using the Quantity One 4.6.2 software (Bio-Rad).

\section{TL measurement by quantitative real-time PCR methodology}

The measurement of TL by qPCR was carried out as described previously (Harle-Bachor \& Boukamp 1996). Genomic DNA was extracted from the GCs using the PureLink Genomic DNA Kit (Invitrogen), and its quantity and quality were determined by 260/280 u.v. spectrophotometry. After extraction, the isolated DNA samples were stored at $-80{ }^{\circ} \mathrm{C}$ until analysis. The TL of the DNA samples was determined using the quantitative real-time amplification procedure described previously (Cawthon 2002), with the following modifications. Standard curves are shown in Fig. 2. All the samples, including the reference DNA sample, were analysed using a LightCycler 480 system (Roche). The qPCRs were carried out in triplicate using $20 \mu \mathrm{l}$ of a solution
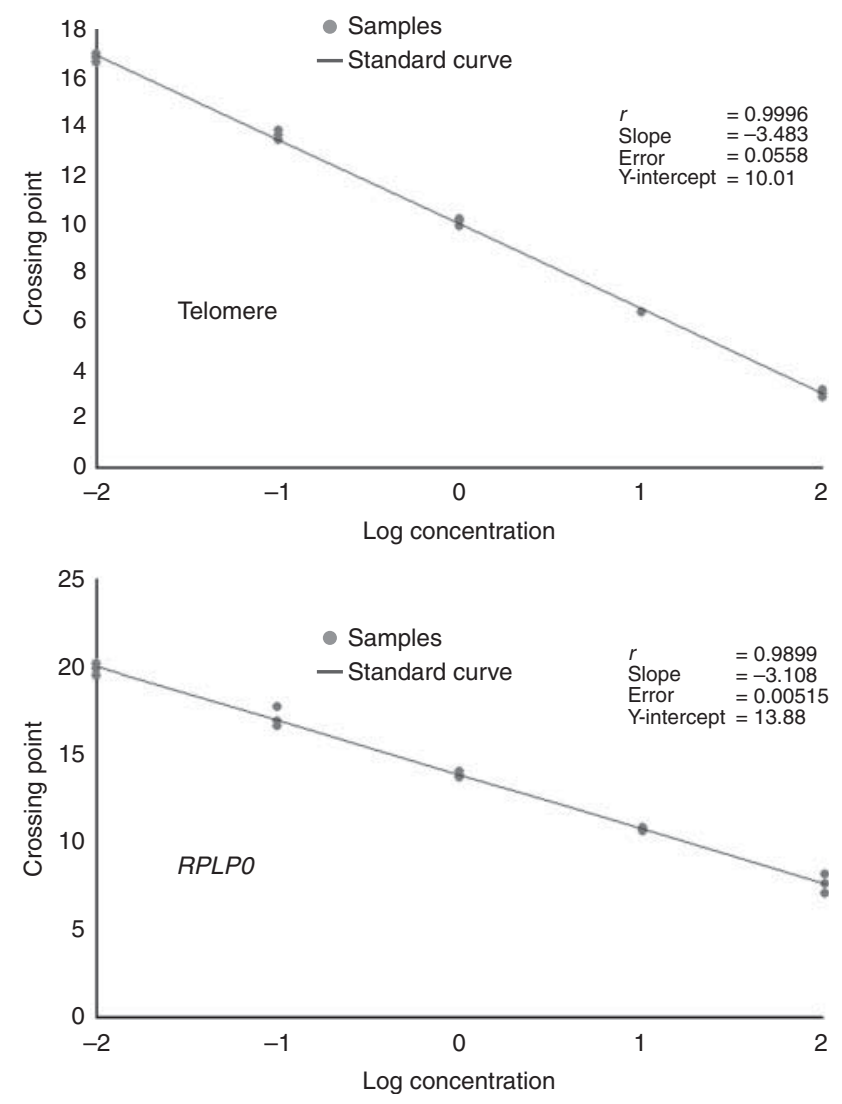

Figure 2 Standard curves used to measure the relative T:S ratio. Five DNA concentrations over a tenfold range were generated by serial dilution from $2.08 \times 10^{-4}$ to $2.08 \mathrm{ng} / \mu \mathrm{l}$ and aliquoted into the wells of a microtitre plate; the final amounts per well ( $35 \mathrm{ng}$ of the DNA sample) with the middle quantity approximately matching that of the samples were assayed. The $C$ t of a DNA sample is the fractional number of PCR cycles to which the sample must be subjected to accumulate enough products to cross a set threshold of magnitude of fluorescent signal. Any individual or pooled human DNA sample may be used to create the standard curves, as long as the $C t$ of each assayed sample falls within the range of $C t$ values of the standard curves. The ratio of the telomere repeat copy number $(\mathrm{T})$ to the single-copy gene copy number $(\mathrm{S})$. 


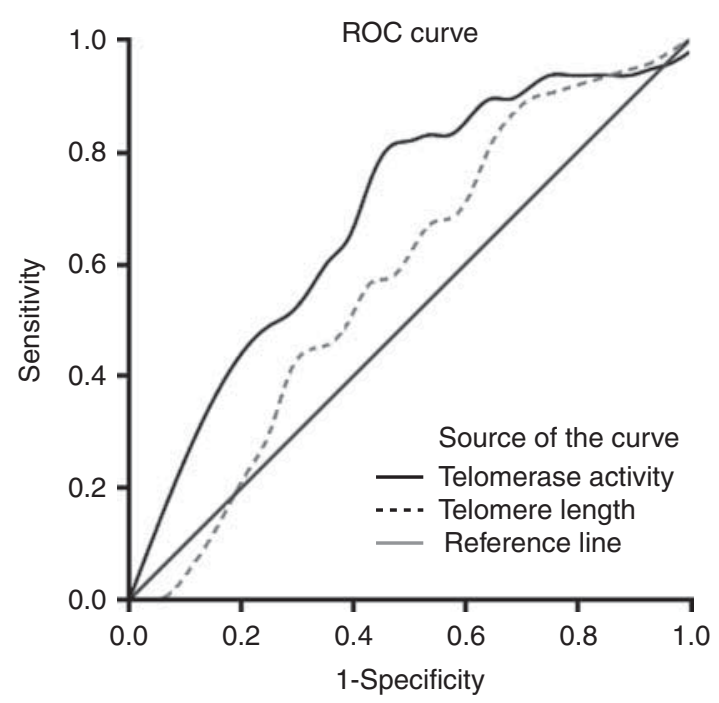

Figure 3 ROC curves for TA and TL. Diagonal segments were produced by ties.

containing the following: $35 \mathrm{ng}$ of the DNA sample, $1 \times$ SYBR Green Mix (TAKARA), $0.2 \mu \mathrm{M}$ of the telomere forward primer (5'-CGG TTT GTT TGG GTT TGG GTT TGG GTT TGG GTT TGG GTT- $\left.3^{\prime}\right)$ and $0.2 \mu \mathrm{M}$ of the telomere reverse primer $\left(5^{\prime}\right.$ GGC TTG CCT TAC CCT TAC CCT TAC CCT TAC CCT TAC CCT$\left.3^{\prime}\right)$. The single-copy RPLPO gene, which encodes the acidic ribosomal phosphoprotein PO, was used as the amplification reference gene. Primers for this gene were added to obtain a final concentration of $0.2 \mu \mathrm{M}$. The forward primer was RPLPOu $\left(5^{\prime}-\right.$ CAG CAA GTG GGA AGG TGT AATCC- $\left.3^{\prime}\right)$ and the reverse primer was 36B4d $\left(5^{\prime}\right.$-CCC ATT CTA TCA TCA ACG GGT ACAA$\left.3^{\prime}\right)$. For both the telomere and 36B4 products, the cycling conditions were $30 \mathrm{~s}$ at $95^{\circ} \mathrm{C}$, followed by 40 cycles of $95^{\circ} \mathrm{C}$ for $5 \mathrm{~s}, 60^{\circ} \mathrm{C}$ for $20 \mathrm{~s}$ and $83{ }^{\circ} \mathrm{C}$ for $5 \mathrm{~s}$. All the transition rates were set to $4{ }^{\circ} \mathrm{C} / \mathrm{s}$. One standard curve was generated for each plate. We generated standard curves for all the plates as shown in Fig. 2. The reference gene was RPLPO and the target gene was the telomere. Additionally, we chose one sample divided into two parts for testing in two plates to correct for variance between the two plates. Each sample was spotted in three wells. Positive controls and negative controls were included in each plate. The standard curves for telomere and RPLPO were generated by the LightCycler software using the second derivative method $\left(\left(2^{C \text { (telomeres) }} / 2^{C(36 \mathrm{~B} 4)}\right)^{-1}=2^{-\Delta C_{\mathrm{t}}}\right)$. The single-copy gene amplification reaction products from a reference DNA sample were serially diluted tenfold with DNase/RNase-free water (Promega) to obtain five concentrations of DNA ranging from $2.08 \times 10^{-4}$ to $2.08 \mathrm{ng} / \mu \mathrm{l}$. The ratio of the telomere repeat copy number $(\mathrm{T})$ to the single-copy gene copy number $(\mathrm{S})$, which is proportional to the average $\mathrm{TL}$ in each sample, was then determined using the standard curve method.

\section{Hormone assays}

Blood samples were obtained from each patient before the initiation of a stimulation cycle, either during days $1-5$ of the menstrual cycle or during the treatment process, depending on follicular development. Beckman Coulter UniCel DxI 800 and the associated reagents (Beckman Coulter, Los Angeles, CA, USA) were used to determine serum sex hormone levels by chemiluminescence. Serum specimens that were not immediately assayed were stored at $-80{ }^{\circ} \mathrm{C}$ until use.

\section{TA assay by TRAP-ELISA}

From January to April 2013, we continued to collect GCs from $\sim 50$ patients. However, only 22 specimens yielded a sufficient number of GCs. TRAP-ELISA was performed using the telomerase kit Telo TAGGG Telomerase PCR ELISA PLUS (Roche Diagnostics) according to the manufacturer's instructions. For negative controls, values routinely obtained are $<0.1$ $\mathrm{A}_{450 \mathrm{~nm}}-\mathrm{A}_{690 \mathrm{~nm}}$ units. For positive controls, the values obtained with $1 \mu \mathrm{l}$ of the control template, low, and $1 \mathrm{ml}$ of the control template, high, should be in the range of $0.2-0.5$ and 2.0-4.0 respectively after $10-\mathrm{min}$ substrate reaction. All the samples were analysed three times, and absorbance values are reported as the $A_{450 \mathrm{~nm}}$ and $A_{690 \mathrm{~nm}}$ readings and the final values as TA $\Delta \mathrm{A}=\mathrm{A}_{450 \mathrm{~nm}}-\mathrm{A}_{690 \mathrm{~nm}}$. After validation of the method with these samples, an assay of samples obtained from 22 patients was carried out. These 22 samples were also used for determining TA and TL based on the methods described above.

\section{Statistical analyses}

Statistical analyses were carried out using the SPSS 16.0 software. The normally distributed data are reported as the mean \pm S.E.M., and the non-normally distributed data are reported as the median (range). The pregnant and non-pregnant groups were compared using independent-samples $t$-test or a Mann-Whitney $U$ test depending on data distribution. Blastocyst transfer rates were compared using the Pearson $\chi^{2}$ test. A binary logistic regression model was used to determine the pregnancy probability. The likelihood ratio test was used to calculate the significance of the regression model, and the Nagelkerke $R^{2}$ coefficient was used to evaluate and explain the variance. Receiver operating characteristic (ROC) curves were used to analyse the predictive values of TL and TA for clinical pregnancy, and their accuracies were evaluated by sensitivity, specificity and Youden's index. Significance was defined as a (two-tailed) $P$ value $<0.05$.

\section{Results}

\section{Clinical characteristics of the study subjects}

The mean age of the subjects was $30.49 \pm 0.46$ years, the mean BMI was $21.00 \pm 0.49 \mathrm{~kg} / \mathrm{m}^{2}$ and the mean basal $\mathrm{FSH}(\mathrm{bFSH})$ level was 6.71 $\pm 0.17 \mathrm{IU} / \mathrm{l}$. A significant difference in basal serum FSH level was found between the two groups: $6.61 \pm 0.47 \mathrm{IU} / \mathrm{I}$ in the pregnant group vs $7.58 \pm 0.32 \mathrm{IU} / \mathrm{I}$ in the non-pregnant group $(P<0.025)$. The peak $E_{2}$ level was lower in the pregnant group than in the non-pregnant group $(2665.40 \pm 396.21 \mathrm{vs}$ $2766.27 \pm 563.36, P<0.034)$. The groups did not differ significantly by age, BMI, basal $\mathrm{LH}_{2} \mathrm{E}_{2}$, and $\mathrm{T}$ levels, starting and total $\mathrm{G}$ dose, or Gn stimulation duration $(P>0.05$; as shown in Table 1$)$. 
Table 1 Subject baseline characteristics and controlled ovarian stimulation data.

\begin{tabular}{|c|c|c|c|c|}
\hline Characteristics & Pregnant group $(n=29)$ & Non-pregnant group $(n=47)$ & $\boldsymbol{F}^{\mathrm{a}} / \boldsymbol{Z}^{\mathrm{b}}$ & $P$ value \\
\hline Age (years) ${ }^{\mathrm{c}}$ & $29.13 \pm 1.32$ & $28.80 \pm 1.74$ & 0.001 & 0.149 \\
\hline $\mathrm{BMI}\left(\mathrm{kg} / \mathrm{m}^{2}\right)^{\mathrm{C}}$ & $22.50 \pm 1.32$ & $19.62 \pm 0.92$ & 2.377 & 0.425 \\
\hline Basal serum FSH $(\mathrm{IU} / \mathrm{l})^{\mathrm{c}, \mathrm{d}}$ & $6.61 \pm 0.47$ & $7.58 \pm 0.32$ & 2.125 & $<0.025$ \\
\hline Basal serum LH (IU/I) $)^{\mathrm{c}}$ & $3.50 \pm 0.44$ & $4.68 \pm 1.03$ & 0.679 & 0.353 \\
\hline Basal serum $E_{2}(\mathrm{pg} / \mathrm{ml})^{\mathrm{e}}$ & $37.20(16.69-363.82)$ & $30.07(16.33-72.77)$ & -0.692 & 0.489 \\
\hline Serum $\mathrm{T}(\mathrm{nmol} / /)^{\mathrm{c}^{\mathrm{C}}}$ & $1.35 \pm 0.13$ & $1.38 \pm 0.17$ & 1.046 & 0.336 \\
\hline PRL & $13.33 \pm 2.20$ & $18.26 \pm 4.12$ & 0.987 & 0.740 \\
\hline Starting Gn dose $(\mathrm{IU})^{\mathrm{e}}$ & $150(100-225)$ & $112.50(100-300)$ & -0.964 & 0.335 \\
\hline Total Gn dose (IU) $)^{\mathrm{C}}$ & $1884.38 \pm 266.13$ & $1807.50 \pm 479.77$ & 1.756 & 0.394 \\
\hline Duration of $\mathrm{COH}$ stimulation (days) & $11.5(7-12)$ & $12(7-12)$ & -1.352 & 0.176 \\
\hline Peak oestradiol level $(\mathrm{pg} / \mathrm{ml})^{\mathrm{c}, \mathrm{d}}$ & $2665.40 \pm 396.21$ & $2766.27 \pm 563.36$ & 6.173 & $<0.034$ \\
\hline
\end{tabular}

$\mathrm{FSH}$, follicle-stimulating hormone; $\mathrm{LH}$, luteinizing hormone.

${ }^{\mathrm{a}}$ For the Pearson $\chi^{2}$ test. ${ }^{\mathrm{b}}$ For the Mann-Whitney $U$ test. ${ }^{\mathrm{C}}$ Values are mean \pm s.D. ${ }^{\mathrm{d}} \mathrm{A}$ significant difference was detected between the pregnant group and the non-pregnant group by the independent-samples $t$-test. $(P<0.05)$. 'Values are medians (ranges).

\section{TL, TA and IVF laboratory parameters}

The TA, number of retrieved oocytes and rate of blastocyst transfer were higher in the pregnant group $(0.8825 \mathrm{OD} \times \mathrm{mm}, 12.75 \pm 2.20$ and $34.48 \%$ respectively) than in the non-pregnant group $(0.513 \mathrm{OD} \times \mathrm{mm}$, $11.60 \pm 0.93$ and $14.89 \%$ respectively) $(P<0.05)$. The TLs and numbers of retrieved oocytes, mature oocytes, two pronuclei and good-quality embryos were comparable between the two groups $(P>0.05$; as shown in Table 2).

\section{Correlations between TL and TA and the clinical pregnancy rate}

The associations between TL and TA and the clinical pregnancy rate were analysed by binary logistic regression and were assessed by the odds ratios (ORs) $(\operatorname{Exp}(B))$ and $95 \%$ Cls. Given that age, basal serum FSH level, $\mathrm{BMI}$, total $\mathrm{Gn}$ dose, peak $\mathrm{E}_{2}$ level, $\mathrm{LH}$ and $\mathrm{FSH}$ levels on the day of HCG injection, and number of retrieved oocytes may have confounded the associations with the pregnancy rate, these variables were included in a multivariate regression equation using a forward stepwise (conditional) method. After adjusting for the confounding factors, we found that a TA increase of $1 \mathrm{OD} \times \mathrm{mm}$ increased the pregnancy probability by 4.769-fold (OR: $5.769,95 \%$ Cl: 1.434-23.212, $P<0.014$ ) and that the OR coefficient for the peak $E_{2}$ level was 0.999 (95\% Cl: 0.998-1.000, $P<0.002)$. There were no significant correlations between TL, age, basal serum FSH level, total $\mathrm{Gn}$ dose or $\mathrm{Gn}$ stimulation duration and clinical pregnancy rate $(P>0.05$; as shown in Table 3$)$.

\section{Predictive value of TL and TA for clinical pregnancy}

The areas under the ROC curve were 0.576 (Youden's index: 0.21 , sensitivity: $85 \%$, and specificity: $36 \%$ ) for TL and 0.674 (Youden's index: 0.38 , sensitivity: $81.0 \%$, and specificity: $57.0 \%)$ for TA ( $P=0.271$ and $P<0.012$ respectively). The ROC curves are shown in Fig. 3.

Table 2 Telomere length, telomerase activity and IVF laboratory parameters.

\begin{tabular}{|c|c|c|c|c|}
\hline Variables & Pregnant group $(n=29)$ & Non-pregnant group $(n=47)$ & $F^{a} / Z^{b}$ & $P$ value \\
\hline TL (T:S ratio) & $3.60 \pm 0.84$ & $3.18 \pm 0.70$ & 3.18 & 0.154 \\
\hline $\mathrm{TA}(\mathrm{OD} \times \mathrm{mm})^{\mathrm{C}}$ & $0.8825(0-1.33)$ & $0.513(0-1.54)$ & -2.679 & $<0.007$ \\
\hline Retrieved oocytes $(n)$ & $12.75 \pm 2.20$ & $11.60 \pm 0.93$ & 0.277 & 0.045 \\
\hline Metaphase II oocytes $(n)$ & $10.50 \pm 1.66$ & $9.40 \pm 1.17$ & 0.149 & 0.216 \\
\hline Proportion of mature oocytes $(\%)^{c}$ & $85.71(\overline{57}-100)$ & $90.19(4-100)$ & -0.622 & 0.534 \\
\hline Number of two pronuclei & $8.93 \pm 1.28$ & $7.60 \pm 1.32$ & 0.643 & 0.133 \\
\hline Fertilisation rate $(\%)^{\mathrm{c}}$ & $77.27(29-100)$ & $83.77(8-100)$ & -1.236 & 0.216 \\
\hline Proportion of good-quality embryos $(\%)^{\mathrm{C}}$ & $21.05(0-67)$ & $22.48(0-68)$ & -0.604 & 0.546 \\
\hline Utilisation rate of embryos (\%) & $72.88 \pm 3.62$ & $67.35 \pm 2.93$ & 0.004 & 0.24 \\
\hline Rate of blastocyst transfer $(\%)^{\mathrm{d}, \mathrm{e}}$ & $34.48(10 / 29)$ & $14.89(7 / 47)$ & 3.963 & $<0.047$ \\
\hline
\end{tabular}

The fertilisation rate was calculated using one of the following expressions: (number of mono-pronuclei + number of two pronuclei + number of multi-pronuclei + number of late-cleavage nuclei)/number of oocytes retrieved when IVF cycles were performed or (number of mono-pronuclei+ number of two pronuclei + number of multi-pronuclei)/number of metaphase II oocytes when ICSI cycles were performed. The embryo utilisation rate was calculated using the following expression: (number of cryopreserved embryos + number of embryos transferred)/number of oosperm. The blastocyst transfer rate was calculated as the fraction of blastocysts transferred out of the total number of embryos transferred. Consistent with previously published findings, a high-quality embryo was defined by the absence of multinucleated blastomeres, four or five blastomeres on day 2 , seven or more cells on the following day, and <20\% fragments (Van Royen E et al. 1999 and Ebner et al. 2003).

abased on the Pearson $\chi^{2}$ test; ${ }^{b}$ based on the Mann-Whitney $U ;{ }^{C}$ Values are medians (ranges) and were compared using the Mann-Whitney $U$ test. ${ }^{d}$ Values are percentages and were compared using the Pearson $\chi^{2}$ test. ${ }^{\mathrm{e}} \mathrm{A}$ significant difference was detected between the pregnant group and the non-pregnant group by the independent-samples $t$-test $(P<0.047)$. 
Table 3 Associations between the stepwise regression variables and the clinical pregnancy rate.

\begin{tabular}{|c|c|c|c|c|}
\hline Variables & $\begin{array}{c}\text { Coefficient } \\
(B)\end{array}$ & $\begin{array}{c}\text { OR }(\operatorname{Exp}(B)) \\
(95 \% \mathrm{Cl})\end{array}$ & $\begin{array}{c}\text { Wald } \\
\left(\chi^{2}\right)\end{array}$ & $P$ value \\
\hline $\begin{array}{l}\text { Telomerase } \\
\text { activity }\end{array}$ & 1.753 & $\begin{array}{c}5.769 \\
(1.434-23.212)\end{array}$ & 6.088 & $<0.014$ \\
\hline Total Gn dose & -0.001 & $\begin{array}{c}0.999 \\
(0.998-1.000)\end{array}$ & 3.754 & 0.053 \\
\hline $\begin{array}{l}\text { LH level on the } \\
\text { day of HCG } \\
\text { injection }\end{array}$ & 0.000 & $\begin{array}{c}1.000 \\
(0.999-1.000)\end{array}$ & 0.155 & 0.694 \\
\hline $\begin{array}{l}\text { Peak oestradiol } \\
\text { level }\end{array}$ & 0.000 & $\begin{array}{c}0.999 \\
(0.998-1.000)\end{array}$ & 9.526 & $<0.002$ \\
\hline Constant & 4.034 & 56.462 & 5.347 & 0.021 \\
\hline
\end{tabular}

Telomere length, telomerase activity, age, basal FSH level, BMI, total Gn dose, peak oestradiol level, LH and FSH levels on the day of HCG injection, and number of retrieved oocytes were retained in the forward stepwise (conditional) logistic regression equation and were treated as continuous variables. Telomerase activity and peak oestradiol level were significant. The $-2 \log$ likelihood value was 61.364 and the Nagelkerke $R^{2}$ value was 0.41 .

The corresponding cut-off points were 4.47 for TL and $0.65 \mathrm{OD} \times \mathrm{mm}$ for TA (Table 4). These results demonstrated that TA predicts pregnancy outcomes following IVF treatment better than TL. No other clinical parameters, including age, bFSH level or peak $\mathrm{E}_{2}$ level, distinguished between the pregnant group and the nonpregnant group as effectively as TA.

\section{Methodologies}

\section{Validation of TA assessment using ELISA}

We obtained results for 22 samples after statistical analysis of their data. There was agreement between the results obtained using ELISA and those obtained using ELISA and those obtained on using non-denaturing polyacrylamide gel silver staining. Spearman's correlation revealed these two methods to be concordant $(r=0.917, P<0.05)$. Then, we further compared the data obtained from the 22 specimens of the pregnant group and the non-pregnant group. The results indicated that TA in the pregnant group was significantly higher than that in the non-pregnant group as assessed by the two methods (Table 5 and Fig. 4). We compared the squares of the ROC curve for TA (by ELISA and native PAGE respectively) and TL. The area of ROC curve for TA as determined by ELISA was 0.497 , that for TA as determined by native PAGE was 0.528, and that for TL was 0.090.

\section{Discussion}

According to classical theories, TA and TL are thought to be associated with age (Keefe 2007, Keefe et al. 2007). Thus, this study was designed to restrict the cohort age range to diminish the age effect on TA. Consequently, there were no significant differences between the study subjects with regard to age. However, this factor does not contradict the theory that TA and TL are related to age.
Thus, only IVF patients with fallopian tube occlusion who were aged 23-38 years were recruited.

The reason for selecting luteinized GCs for the prediction of IVF treatment outcomes and for the evaluation of egg and embryo quality is that the egg is fertilised to form the embryo for the purpose of embryo transfer; a large number of luteinized GCs are typically discarded. In addition, the development of GCs is synchronised with that of oocytes, and it can indirectly reflect the development of oocytes. We analysed both telomere parameters, TL and TA, simultaneously for each patient. Our data indicated that TA predicts pregnancy outcomes following IVF treatment better than TL. The cases were divided into a pregnant group and a non-pregnant group, thereby facilitating the identification of unique clinical features for patients with each pregnancy outcome. As shown in Table 1, the two groups exhibited no significant differences with regard to a variety of parameters including age, BMI, basal serum $\mathrm{LH}$ level, basal serum $\mathrm{E}_{2}$ level, serum $\mathrm{T}$ level, starting dose of $\mathrm{Gn}$, total dose of $\mathrm{Gn}$, duration of controlled ovarian hyperstimulation $(\mathrm{COH})$ (days) and peak $\mathrm{E}_{2}$ level. The traditional view holds that bFSH level reflects the ovarian reserve and can predict IVF treatment outcomes (Brodin et al. 2009). Our data were in agreement with those of a study carried out by Kassab et al. (2009), in which it was demonstrated that the bFSH level is significantly correlated with the clinical pregnancy rate. However, other studies have argued that $\mathrm{bFSH}$ level is not adequate to predict IVF treatment outcomes because bFSH level elevation may coincide with a good ovarian response (Thum et al. 2009).

In most cells, TL is correlated with cell division potential such that the shorter the length, the older the cells (Mondello et al. 1997, Baird et al. 2003, Keefe et al. 2007). Human tissues often display age-dependent telomere shortening (Keefe \& Liu 2009, Takubo et al. 2010). A lack of GC TA has been found to be associated with occult ovarian insufficiency (Butts et al. 2009). Our previous study suggested that patients with higher levels of TA in the GCs had a greater likelihood of becoming pregnant than those with less TA. In the present study, we compared both TA and TL in GCs obtained from the same individuals, and we found that TA predicts IVF

Table 4 Predictive values of telomere length and telomerase activity for pregnancy.

\begin{tabular}{lcc}
\hline Parameters & Telomerase activity & Telomere length \\
\hline Area under the & 0.674 & 0.576 \\
$\quad$ ROC curve & & \\
Cut-off point & 0.650 & 4.470 \\
Sensitivity (\%) & 81.0 & 85.0 \\
Specificity (\%) & 57.0 & 36 \\
Youden's index $_{\text {S.E.M. }}$ & 0.38 & 0.207 \\
$P$ value $^{\mathrm{a}}$ & 0.066 & 0.072 \\
\hline
\end{tabular}

${ }^{a}$ The null hypothesis was true area $=0.5$. 
Table 5 TA assessment using native PAGE and ELISA.

\begin{tabular}{|c|c|c|c|c|}
\hline & $\begin{array}{c}\text { Pregnant group } \\
(n=4)\end{array}$ & $\begin{array}{l}\text { Non-pregnant } \\
\text { group }(n=18)\end{array}$ & $\boldsymbol{F}^{\mathrm{a}}$ & $P$ value \\
\hline $\begin{array}{l}\text { Native PAGE } \\
\quad(\mathrm{OD} \times \mathrm{mm})\end{array}$ & $0.58 \pm 0.28^{b}$ & $0.13 \pm 0.06^{\mathrm{b}}$ & 4.30 & $<0.05$ \\
\hline $\begin{array}{c}\text { ELISA }\left(\mathrm{A}_{450 \mathrm{~nm}^{-}}\right. \\
\left.\mathrm{A}_{690 \mathrm{~nm}}\right)\end{array}$ & $0.109 \pm 0.02^{b}$ & $0.069 \pm 0.003^{b}$ & 9.47 & $<0.05$ \\
\hline
\end{tabular}

${ }^{\mathrm{a}}$ Based on the independent-samples $t$-test. ${ }^{\mathrm{b}}$ Values are means \pm s.D.

treatment outcomes better than TL. We considered TA to be more significant than TL and that it may be a potential biomarker of IVF treatment outcomes. However, the sample size was so limited (76 cases) that we did not observe the normal range of TA in reproductive-age women. Previous studies have indicated that TL is positively correlated with reproductive potential (Aydos et al. 2005). TL has been reported to be superior to many clinical parameters for the prediction of post-IVF pregnancy outcomes including bFSH level, age and BMI (Aydos et al. 2005, Keefe et al. 2007). Telomeric DNA deficiency is associated with genomic instability in somatic cells and plays a role in the development of the aneuploidies commonly found in female germ cells and human embryos (Treff et al. 2011). Interestingly, some studies have revealed that patients with recurrent spontaneous abortions had shorter TLs. However, other studies reported that the TLs of premature ovarian failure patients were longer that those of the control group (Hanna et al. 2009). Additional studies reported that infertile women undergoing $\mathrm{COH}$ treatment had significantly longer telomeres than healthy women of a similar age (Dorland et al. 1998). In general, most studies are in agreement that female fertility disorders are likely to be associated with fewer cell divisions. A possible explanation is that the cells may have prolonged cellcycle durations. This controversy also indicated that TL alone was not enough to fully reveal the reproductive potential when we compared the pregnant group and the non-pregnant group. Moreover, the two groups were relatively indistinguishable in terms of the numbers of harvested oocytes, the proportion of mature eggs, the fertilisation rate, the embryonic cleavage rate, and the proportion of high-quality embryos (Table 2). By contrast, the data given in Table 3 revealed that TA was positively correlated with the pregnancy rate such that an increase of every $1 \mathrm{OD} \times \mathrm{mm}$ in TA resulted in a 4.769-fold increased likelihood of becoming pregnant. Many factors have previously been implicated in IVF treatment outcomes, such as TL, age, bFSH level, BMI, total $\mathrm{Gn}$ dose, peak $\mathrm{E}_{2}$ level, $\mathrm{LH}$ and FSH levels on the day of HCG injection, and number of retrieved oocytes, but these factors did not affect post-IVF pregnancy rates. Together, the data suggest that TA is a better indicator of pregnancy outcomes than other factors and that TL alone is not a sufficient proxy for ovarian reserves and reproductive potential. Importantly, our results reveal clear differences in comparison with the data reported by Aydos et al. (2005). These authors examined peripheral leucocytes in women who were $\sim 50$ years old and investigated the associations between TL and reproductive lifespan. By contrast, in the present study, we examined GCs, which grow synchronously with oocytes, and restricted the age of the subjects to $<38$ years. Although there was no effect of TL on pregnancy outcomes, TA was higher in the pregnant group than in the non-pregnant group. Therefore, telomere shortening may be compensated for by an elevation of TA. Dong et al. (2005) suggested that telomerase may be re-activated when cells suffer from a crisis to stabilise the TLs. Only clones with stabilised telomeres, which apparently occurs by the activation of telomerase, have been found to continue to proliferate indefinitely (Counter et al. 1994).

Thus far, there are no reports explicitly comparing TA and TL with regard to cellular proliferative and differentiation potentials. Telomerase can compensate for telomere shortening resulting from cell division, maintain genetic integrity (Mondello et al. 1997) and synthesise TTAGGG repeats, which assists in the prevention of chromosomal fusion (Mondello et al. 1997, Cottliar \& Slavutsky 2001). Treff et al. (2011) studied several SNPs in the hTERT gene, rs2736122, rs4246742, rs4975605, rs10069690, rs2736100,
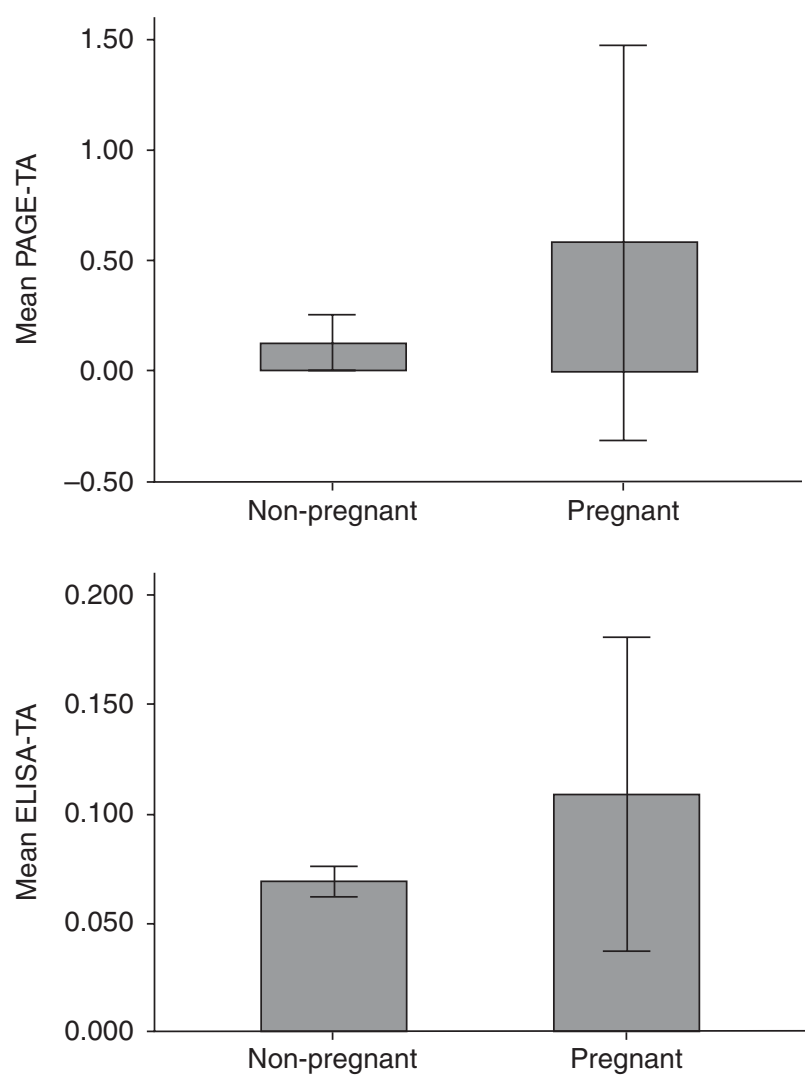

Figure 4 Means of TA obtained in native PAGE and ELISA. 
rs2853676 and rs7726159, and examined changes in TL. Moreover, Choudhary et al. (2012) proposed that the postnatal decrease in TA leads to telomere shortening, which contributes to senescence. Further analysis of the expression of the major telomerase genes TERTand TERC would help validate the TA assay carried out in this study. This analysis might suggest that the alteration of TA precedes the alteration of TL.

Our data indicated that the pregnant group had significantly higher average TA and rates of blastocyst transfer than the non-pregnant group. TA predicts the post-IVF treatment outcome better than $\mathrm{TL}$, which is statistically indistinguishable between the pregnant group and the non-pregnant group. However, because telomerase maintains telomere stability, higher TA leads to longer TL (Hiyama \& Hiyama 2007, Miyashita et al. 2011). Thus, it remains inconclusive whether TA or TL is more important. One possible reason is that the TL and length range as well as the level of TA are yet to be established in a normal proliferative state.

As shown in Table 3, there was no correlation between pregnancy rates and any of the following factors: age, bFSH level, BMI, total Gn dose, peak $\mathrm{E}_{2}$ level, $\mathrm{LH}$ and $\mathrm{FSH}$ levels on the day of HCG injection, and number of retrieved oocytes. Our results indicated that TA, but not $T L$, was significantly correlated with pregnancy outcomes. As illustrated by the ROC curve shown in Fig. 3, TA had a notable impact on post-IVF pregnancy outcomes and was therefore a better pregnancy indicator than TL. For example, some studies have found that mutations in the RNA template for telomerase could be passed onto the corresponding telomere fragments. These mutated telomeres may result in a pre-anaphase cell-cycle arrest phenotype, indicating that TL might not change immediately in response to an alteration in TA (Blackburn 2005). Liu et al. (2002) discovered that infertility in telomerase knockout mice is associated with gradual telomere shortening. These observations have implicated $T L$ and TA in infertility because impairment of the elongation and maintenance of telomeres may eventually lead to infertility. Some scholars (Cao et al. 2002, Calado \& Chen 2006) have hypothesised that telomerase also plays an essential role in cell viability. Some studies (Yamagata et al. 2002) have suggested that telomerase in GCs possibly plays an important role in the maintenance of the normal development of ovarian follicles, as it plays versatile roles in various reproduction pathways.

Based on the reliability of the methodologies used for TA assessment, we referred to the methods and followed the process described in the papers that had been published (Kim et al. 1994, Harle-Bachor \& Boukamp 1996). Furthermore, we used ELISA to validate our methods using 22 new samples, and the results obtained on using the methodologies (ELISA and non-denaturing polyacrylamide gel silver staining) were found to be in agreement. This indicates that TA assessment was reliable. Due to the limitation of the sample size (22 samples), there might be certain bias. We feel that the semiquantitative method (non-denaturing polyacrylamide gel silver staining) is not a perfect method, and we will use ELISA to test TA in the specimens in the next study. All the patients recruited in this study were aged $<38$ years, and thus the sample size should be expanded to evaluate the outcomes of pregnancy for IVF-recipient women belonging to a wider age range group. Thus, TL and TA values that are more indicative for the general population should be generated for predicting pregnancy outcomes in the general population.

\section{Declaration of interest}

The authors declare that there is no conflict of interest that could be perceived as prejudicing the impartiality of the research reported.

\section{Funding}

This study was supported in part by grants from the Science Technology Research and Development Project of Guangdong Province (2010B031600043), the Foundation of Science Research of Population and Family Planning Commission of Guangdong Province (2009231) and the National Science Technology Research Project (81070466) in China.

\section{Acknowledgements}

The authors thank Mo Yaqin, $\mathrm{PhD}$, and Wang Jing for laboratory technical assistance and Huang Baoyun for data collection.

\section{References}

Aydos SE, Elhan AH \& Tukun A 2005 Is telomere length one of the determinants of reproductive life span. Archives of Gynecology and Obstetrics 272 113-116. (doi:10.1007/s00404-004-0690-2)

Baird DM, Rowson J, Wynford-Thomas D \& Kipling D 2003 Extensive allelic variation and ultrashort telomeres in senescent human cells. Nature Genetics 33 203-207. (doi:10.1038/ng1084)

Blackburn EH 2001 Switching and signaling at the telomere. Cell 106 661-673.

Blackburn EH 2005 Telomeres and telomerase: their mechanisms of action and the effects of altering their functions. FEBS Letters 579 859-862. (doi:10.1016/j.febslet.2004.11.036)

Brodin T, Bergh T, Berglund L, Hadziosmanovic N \& Holte J 2009 High basal LH levels in combination with low basal FSH levels are associated with high success rates at assisted reproduction. Human Reproduction 24 2755-2759. (doi:10.1093/humrep/dep254)

Butts S, Shaunik A, Menon S, Riethman H, Coutifaris C \& Barnhart K. 2006. Telomere length and the aging granulosa cell: Correlation with diminished ovarian reserve. Fertility and Sterility 86, Supplement 1, S406.

Butts S, Riethman H, Ratcliffe S, Shaunik A, Coutifaris C \& Barnhart K 2009 Correlation of telomere length and telomerase activity with occult ovarian insufficiency. Journal of Clinical Endocrinology and Metabolism 94 4835-4843. (doi:10.1210/jc.2008-2269)

Calado RT \& Chen J 2006 Telomerase: not just for the elongation of telomeres. Bioessays 28 109-112. (doi:10.1002/bies.20365)

Cao Y, Li H, Deb S \& Liu JP 2002 TERT regulates cell survival independent of telomerase enzymatic activity. Oncogene 21 3130-3138. (doi:10.1038/ sj.onc.1205419)

Cawthon RM 2002 Telomere measurement by quantitative PCR. Nucleic Acids Research 30 e47. (doi:10.1093/nar/30.10.e47) 
Chen H, Wang W, Mo Y, Ma Y, Ouyang N, Li R, Mai M, He Y, Bodombossou-Djobo MM \& Yang D 2011 Women with high telomerase activity in luteinised granulosa cells have a higher pregnancy rate during in vitro fertilisation treatment. Journal of Assisted Reproduction and Genetics 28 797-807. (doi:10.1007/s10815-011-9600-2)

Choudhary B, Karande AA \& Raghavan SC 2012 Telomere and telomerase in stem cells: relevance in ageing and disease. Frontiers in Bioscience 4 16-30. (doi:10.2741/S248)

Cottliar AS \& Slavutsky IR 2001 Telomeres and telomerase activity: their role in aging and in neoplastic development. Medicina 61 335-342.

Counter CM, Botelho FM, Wang P, Harley CB \& Bacchetti S 1994 Stabilization of short telomeres and telomerase activity accompany immortalization of Epstein-Barr virus-transformed human B lymphocytes. Journal of Virology 68 3410-3414.

Dong CK, Masutomi K \& Hahn WC 2005 Telomerase: regulation, function and transformation. Critical Review in Oncology and Hematology 54 85-93. (doi:10.1016/j.critrevonc.2004.12.005)

Dorland M, van Kooij RJ \& te Velde ER 1998 General ageing and ovarian ageing. Maturitas 30 113-118. (doi:10.1016/S0378-5122(98)00066-8)

Ebner T, Moser M, Sommergruber M \& Tews G 2003 Selection based on morphological assessment of oocytes and embryos at different stages of preimplantation development: a review. Human Reproduction Update 9 251-262.

Hanna CW, Bretherick KL, Gair JL, Fluker MR, Stephenson MD \& Robinson WP 2009 Telomere length and reproductive aging. Human Reproduction 24 1206-1211. (doi:10.1093/humrep/dep007)

Harle-Bachor C \& Boukamp P 1996 Telomerase activity in the regenerative basal layer of the epidermis inhuman skin and in immortal and carcinomaderived skin keratinocytes. PNAS 93 6476-6481. (doi:10.1073/pnas.93. 13.6476)

Hiyama E \& Hiyama K 2007 Telomere and telomerase in stem cells. British Journal of Cancer 96 1020-1024. (doi:10.1038/sj.bjc.6603671)

Kassab A, Sabatini L, Tozer A, Zosmer A, Mostafa M \& Al-Shawaf T 2009 The correlation between basal serum follicle-stimulating hormone levels before embryo cryopreservation and the clinical outcome of frozen embryo transfers. Fertility and Sterility 92 1269-1275. (doi:10.1016/j.fertnstert.2008.08.077)

Keefe DL 2007 Telomeres and meiosis in health and disease. Cellular and Molecular Life Sciences 64 115-116. (doi:10.1007/s00018-006-6462-3)

Keefe DL \& Liu L 2009 Telomeres and reproductive aging. Reproduction, Fertility, and Development 21 10-14. (doi:10.1071/RD08229)

Keefe DL, Marquard K \& Liu L 2006 The telomere theory of reproductive senescence in women. Current Opinion in Obstetrics \& Gynecology 18 280-285. (doi:10.1097/01.gco.0000193019.05686.49)

Keefe DL, Liu L \& Marquard K 2007 Telomeres and aging-related meiotic dysfunction in women. Cellular and Molecular Life Sciences 64 139-143. (doi:10.1007/s00018-006-6466-z)

Kim NW, Piatyszek MA, Prowse KR, Harley CB, West MD, Ho PL, Coviello GM, Wright WE, Weinrich SL \& Shay JW 1994 Specific association of human telomerase activity with immortal cells and cancer. Science 266 2011-2015. (doi:10.1126/science.7605428)

Lavranos TC, Mathis JM, Latham SE, Kalionis B, Shay JW \& Rodgers RJ 1999 Evidence for ovarian granulosa stem cells: telomerase activity and localization of the telomerase ribonucleic acid component in bovine ovarian follicles. Biology of Reproduction 61 358-366. (doi:10.1095/ biolreprod61.2.358)

Liu W \& Zhu GJ 2003 Expression of telomerase in human ovarian luteinized granulosa cells and its relationship to ovarian function. Zhonghua Fu Chan Ke Za Zhi 38 402-404.

Liu L, Blasco M, Trimarchi J \& Keefe D 2002 An essential role for functional telomeres in mouse germ cells during fertilization and early development. Developmental Biology 249 74-84. (doi:10.1006/dbio. 2002.0735)

Miyashita N, Kubo Y, Yonai M, Kaneyama K, Saito N, Sawai K, Minamihashi A, Suzuki T, Kojima T \& Nagai T 2011 Cloned cows with short telomeres deliver healthy offspring with normal-length telomeres. Journal of Reproduction and Development 57 636-642. (doi:10.1262/ jrd.11-017A)

Mondello C, Riboni R, Casati A, Nardo T \& Nuzzo F 1997 Chromosomal instability and telomere length variations during the life span of human fibroblast clones. Experimental Cell Research 236 385-396. (doi:10.1006/ excr.1997.3756)

Takubo K, Aida J, Izumiyama-Shimomura N, Ishikawa N, Sawabe M, Kurabayashi R, Shiraishi H, Arai T \& Nakamura K 2010 Changes of telomere length with aging. Geriatrics \& Gerontology International 10 (Suppl 1) S197-S206. (doi:10.1111/j.1447-0594.2010.00605.x)

Thum MY, Kalu E \& Abdalla H 2009 Elevated basal FSH and embryo quality: lessons from extended culture embryos: raised $\mathrm{FSH}$ and blastocyst quality. Journal of Assisted Reproduction and Genetics 26 313-318. (doi:10.1007/s10815-009-9313-y)

Tomanek M, Chronowska E, Kott T \& Czernekova V 2008 Telomerase activity in pig granulosa cells proliferating and differentiating in vitro. Animal Reproduction Science 104 284-298. (doi:10.1016/j.anireprosci. 2007.02.003)

Treff NR, Su J, Taylor D \& Scott RT Jr 2011 Telomere DNA deficiency is associated with development of human embryonic aneuploidy. PLOS Genetics 7 e1002161. (doi:10.1371/journal.pgen.1002161)

Van Royen E, Mangelschots K, De Neubourg D, Valkenburg M, Van de Meerssche M, Ryckaert G, Eestermans W \& Gerris J 1999 Characterization of a top quality embryo, a step towards single-embryo transfer. Human Reproduction 14 2345-2349.

Wan S, Hann HW, Myers RE, Fu X, Hann RS, Kim SH, Tang H, Xing J \& Yang H 2012 Telomere length in circulating serum DNA as a novel noninvasive biomarker for cirrhosis: a nested case-control analysis. Liver International 32 1233-1241. (doi:10.1111/j.1478-3231.2012.02801.x)

Yamagata Y, Nakamura Y, Umayahara K, Harada A, Takayama H, Sugino N \& Kato H 2002 Changes in telomerase activity in experimentally induced atretic follicles of immature rats. Endocrine Journal 49 589-595. (doi:10. 1507/endocrj.49.589)

Received 22 May 2013

First decision 26 June 2013

Revised manuscript received 21 January 2014

Accepted 28 January 2014 